\title{
Claude Thomasset (dir.), L'écriture du texte scientifique au Moyen Âge
}

\section{Maria Colombo Timelli}

\section{(2) OpenEdition}

10 Journals

\section{Édition électronique}

URL : http://journals.openedition.org/studifrancesi/9120

DOI : 10.4000/studifrancesi.9120

ISSN : 2421-5856

Éditeur

Rosenberg \& Sellier

\section{Édition imprimée}

Date de publication : 1 juin 2008

Pagination : 161

ISSN : 0039-2944

\section{Référence électronique}

Maria Colombo Timelli, «Claude Thomasset (dir.), L'écriture du texte scientifique au Moyen Âge », Studi

Francesi [En ligne], 154 (LII | I) | 2008, mis en ligne le 30 novembre 2015, consulté le 12 janvier 2021.

URL : http://journals.openedition.org/studifrancesi/9120; DOI : https://doi.org/10.4000/studifrancesi. 9120

Ce document a été généré automatiquement le 12 janvier 2021.

\section{(c)}

Studi Francesi è distribuita con Licenza Creative Commons Attribuzione - Non commerciale - Non opere derivate 4.0 Internazionale. 


\title{
Claude Thomasset (dir.), L'écriture du texte scientifique au Moyen Âge
}

\author{
Maria Colombo Timelli
}

\section{RÉFÉRENCE}

CLAUDE THOMASSET (dir.), L'écriture du texte scientifique au Moyen Âge, Paris, PUPS, 2006

(«Cultures et Civilisations Médiévales», 35).

1 D'abord, une mise en garde: malgré le titre affiché sur la couverture, les contributions consacrées au Moyen Âge ne sont qu'au nombre de quatre; l'intitulé correct et complet $\mathrm{du}$ volume ne se lit malheureusement que dans la page de titre: L'écriture du texte scientifique. Des origines de la langue française au XVIII ${ }^{e}$ siècle.

2 Sur la base d'un corpus de textes encyclopédiques du XIII ${ }^{\mathrm{e}}$ siècle parmi lesquels Placides et Timeo joue un rôle de premier plan, Christine sILVI (Fausses et vraies objections dans le discours encyclopédique scientifique au XIII e siècle, pp. 49-78) analyse les formules d'objection tant du point de vue de la structure linguistique que sur le plan actanciel et dans leur fonction pour la transmission du savoir. Elle peut ainsi conclure que le discours scientifique absorbe ce qui se présente comme une objection pour s'enrichir et proposer en réponse une proposition d'autant plus solide qu'elle tient compte de la contestation. De fait, au-delà du procédé du dialogue fictionnel, la voix de l'encyclopédiste est finalement la seule à se faire entendre.

3 Dans son domaine de spécialisation, Joëlle Ducos (Écrire la météorologie au XIII siècle, pp. 79-92) interroge quelques textes encyclopédiques et didactiques comprenant des exposés relatifs à la météorologie. Elle souligne à juste titre comment l'aspect linguistique le plus superficiel de la question (la néologie qu'impose tout passage traductif de la langue du savoir au vulgaire français) ne se comprend réellement que dans le contexte de la divulgation du savoir et de la diffusion de la pensée aristotélicienne. 
4 Bien qu'apparemment limitée à l'étude de la terminologie dans un traité scientifique la Pratike de geometrie, vers 1250-1275 - la contribution de Frankwalt MÖHREN (Les débuts de l'écriture française de la géométrie au XIII siècle, pp. 93-113) est en réalité une réflexion méthodologique de portée bien plus vaste. F.M. montre en effet la spécificité stylistique, syntaxique, morphologique et surtout lexicale de ce texte, mais parvient surtout à montrer comment une étude lexicologique sérieuse ouvre des perspectives sur l'histoire de la langue, de la science, et, plus largement encore, de la culture.

5 Chantal conNochIE-BOURGNE (Mise en récit et discours scientifique: les encyclopédies du XIII siècle en langue vulgaire, pp. 117-131) mène son enquête sur la présence de la dimension narrative dans quatre encyclopédies médiévales: Image du monde, Livres dou Tresor, Sydrac, Placides et Timeo. Elle met en relief spécialement quelques stratégies d'écriture visant à capter dès le seuil de l'œuvre l'attention et l'intérêt du lecteur: table des matières, prologue et épilogue, récit-cadre, mise en scène d'un dialogue fictif, insertion $\mathrm{du}$ discours scientifique dans une chronologie; dans un tel ensemble, l'introduction éventuelle de séquences narratives a pour but d'illustrer ou de confirmer la véridicité et l'exactitude des notions et commentaires présentés. 